\title{
Influence of situational variables on the U'18 soccer performance analysis Análisis de la influencia de las variables situacionales en el rendimiento en futbol U'18
}

*Pablo Caballero, **Javier García-Rubio, *Sergio José Ibáñez

*University of Extremadura (Spain), ** Universidad Autónoma de Chile (Chile)

\begin{abstract}
Team sports performance analysis usually uses samples of high performance teams and athletes. Those studies, although useful to trainers and players, are hardly applicable on different contexts. The goal of this study was to analyze the effects of the situational variables on the final score and competition in youth soccer. To achieve this, all games from a Spanish regional youth soccer league $(\mathrm{n}=132)$ were analyzed. Linear regressions were used to check the influence of situational variables (score difference; final league standings; match location; scoring first; cards; substitutions; quality of opponent and field surface) on the outcome of the game, final team standings and game location. Results show the importance that the match location, scoring first, rival team quality, substitutions and cards have on the match's outcome, meanwhile the linear regression highlights the effect of scoring first, rival team quality, and substitutions on the final team standings.
\end{abstract}

KeyWords: Notational analysis; home advantage; scoring first; quality of opponent.

Resumen. El análisis del rendimiento deportivo en deportes de equipo usa habitualmente muestras equipos y deportistas de alto rendimiento deportivo. Estos estudios, aunque de una gran utilidad para entrenadores y jugadores, son difícilmente aplicables a otros contextos. El objetivo de este estudio fue analizar los efectos de las variables situacionales en el resultado final del partido y la competición en fútbol juvenil. Para ello, se analizaron todos los partidos de una liga de categoría juvenil regional española ( $\mathrm{n}=132)$. Se utilizó la regresión lineal para comprobar la influencia de las variables situacionales (diferencia de goles en el partido; clasificación final del equipo; localización del partido; marcar primero; amonestaciones; sustituciones; la calidad del oponente y la superficie de juego) en el resultado, la clasificación final y la localización del partido. Los resultados ponen de manifiesto la importancia que en el resultado final del partido tiene la localización del partido, anotar primero, la calidad del oponente, las sustituciones y las amonestaciones, mientras que, en la clasificación final, la regresión lineal destaca el efecto de anotar el primer gol, la calidad de la oposición y las sustituciones.

Palabras clave: Análisis Notacional; Ventaja de jugar en casa; Anotar primero; Calidad del oponente.

\section{Introduction}

Studies that analyze the technical and tactical performance indicators on invasion sports, use, in terms of sports and competitions, high quality samples preferably (García-Rubio, Gómez, Lago-Peñas, \& Ibáñez, 2015; Liu, Gómez, Gonçalves, \& Sampaio, 2015). These studies, based on performance analysis, highlighted the importance of identifying the sport's critical events in order to get better results (Gómez, GómezLopez, Lago, \& Sampaio, 2012). Male athletes and teams are used frequently as sample, and the studies that analyze performance indicators on women or young sportsmen are scarce. The results, while being essential for each sport, when transferred to different level populations, age, or gender, only have a limited application. There are just a few studies that analyze these indicators on training sportsmen samples (García, Ibáñez, Feu, Cañadas, \& Parejo, 2008; Lorenzo, Gómez, Ortega, Ibañez, \& Sampaio, 2010), and they are more focused on the physical shape and technic aspects (Brocherie, Girard, Faiss, \& Millet, 2015; Randers, Andersen, Rasmussen, Larsen, \& Krustrup, 2014; Rebelo, Brito, Seabra, Oliveira, \& Krustrup, 2014), or the tactic training methods, like the small-sided games (Aguiar, Goncalves, Botelho, Lemmink, \& Sampaio, 2015; Folgado, Lemmink, Frencken, \& Sampaio, 2014).

It has been shown that some situational variables have a great importance on the final outcome of professional soccer games (GarcíaRubio et al., 2015; Gómez, Lago-Peñas, \& Pollard, 2013; Liu, Hopkins, \& Gómez, 2015), and also on some other team sports like basketball (García, Ibáñez, Gómez, \& Sampaio, 2014; Gómez, Lorenzo, Ibañez, \& Sampaio, 2013), handball (Prieto, Gómez, \& Sampaio, 2016), water polo (Gómez, Serna, Lupo, \& Sampaio, 2016) or volleyball (Marcelino, Mesquita, \& Sampaio, 2011). Among them, the ones that have received more attention between researchers are the location of the match (home or away) (Lago, 2009; Pic \& Castellano, 2017); the rival’s team quality, according to the team standings (Lago-Peñas \& Lago-Ballesteros, 2011); scoring first, the importance of scoring the first goal in the outcome of the match (Sampedro \& Prieto, 2012); the amount of substitutions (Coelho et al., 2012; Rey, Lago-Ballesteros, \& Padrón-Cabo, 2015; Siegle \& Lames, 2012); or the amount of cards (Bar-Eli, Tenenbaum, \&

Fecha recepción: 15-11-16. Fecha de aceptación: 10-03-17 Sergio Ibáñez sibanez@unex.es
Geister, 2006).

It has been proven that, in soccer, local teams (Pollard \& Gómez, 2009), that score first (Lago, 2005) and get booked less (Bar-Eli et al., 2006) are the ones that have the highest chance of winning their games. Also, substituting players to produce interruptions through the game (Siegle \& Lames, 2012), and that those interruptions happen near the end of the match is related to victory too (Rey et al., 2015). All these studies have been done with adult athletes that play on professional soccer leagues. In these competitions all the game field surfaces are standard approved, have similar features (natural grass), adjusted size to some official boundaries, wich makes that all teams, regardless if they play home or away, play in similar terrains and the same surface. In unprofessional leagues, there is more flexibility for each team to participate with a different game field surface (natural grass, dirt, artificial grass), as is the case of the U'18 leagues in Spain. Most of the studies analyzing game field surfaces are focused on the injuries that they can produce (Kristenson et al., 2015; van den Eijnde, Peppelman, Lamers, van de Kerkhof, \& van Erp, 2014), the technical-tactical performance indicators (Sleat, O’Donoghue, Hughes, \& Bezodis, 2016), but, as far as we know, not in the overall performance.

Performance indicators research's results transference is more relevant when it can be applied to the same populations in which they have been investigated. Their use on other ages and genders are yet to be proven. Drust (2010) indicates that some of the limitations on performance tactical-technical indicators/markers (notational analysis) are the amount and diversity of research data to predict performance. Therefore, it is very important to start a line of research that analyses how performance indicators behave on different contexts, like young sportsmen populations. Specifically, the study of situational variables in U'18 soccer performance. For this research the hypothesis are. I) the importance of the game location, the effect of scoring the first goal, the quality of the rival team, number of substitutions and the amount of cards in the match's final score and the final team standings; and II) the importance of these variables on the final score will be different according to the match location. Therefore, the study's objective is double: Analyze the effects of situational variables on the game's final score and final team standings, and to compare the effects of situational variables on the match's final score according to the game location. 


\section{Method}

This research's design is classified as an empiric study with quantitative methodology, specifically, is a descriptive study through an arbitrary observation code. It is a natural and ex post facto study, since the research is being done in the habitual context in which the phenomenon happens, and the researcher doesn't intervene on what he sees (Montero \& León, 2007). This research would be empiric, with a descriptive and observational strategy and a multidimensional nomothetic following design (IV quadrant) (Ato, López, \& Benavente, 2013).

Sample. The sample was composed by all the 2014-2015 season games of a regular regional U'18 soccer league. The competition consists of 12 teams that played two full rounds, with 132 games in total. The data was extracted from the leagues official website (http:// www.fexfutbol.com)

Variables. The analyzed variables were: I) score difference: victory, draw or defeat according to the goal difference between both teams; II) final team standings from 1 to 12; III) game location: if the team plays home (coded as 1) or away (coded as 2); IV) scoring first: this was used as a dummy variable, where 0 is not scoring first and 1 is scoring first; $v$ ) cards: is the number of cards each team gets by game; VI) substitutions: the number of substitutions that every team does by game; VII) rival team quality: is the calculation of the difference between the teams league standings every week during the present season; and finally, VIII) field surface: if the team plays on the same surface(1) or a different one from the regular field they use (0) (dirt, grass, or artificial grass)

Statistical analysis. First of all, a descriptive analysis of the situational variables' effect on the outcome of the game through frequencies and percentages. Finally, to check the influence of every single one of those situational variables, both on the game's outcome and the weekly and final standings, a linear regression was made following this next model: $M 0 / F L S=\beta 1+\beta 2 * S F+\beta 3 * M L+\beta 4 * Q 0+\beta 5 * S+\beta 5 * C$ $+\beta 5 * G F S+\varepsilon i$

Where $\mathrm{MO}=$ Match Outcome; FLS = Final League Standings; SF $=$ Scoring First, $\mathrm{ML}=$ Match Location, $\mathrm{QO}=$ Quality of Opposition; $\mathrm{S}=$ Substitutions; C= Cards; and GFS= Game-Field Surface.

In the final league standings regression, the rival team quality predicting variable was based on the weekly standings, which is a more trustworthy indicator of the team's form for each game. In the match outcome regression, rival team quality was calculated from the league final standings. The Durbin-Watson statistical was used to check the independence of the model's residues. Furthermore, data was controlled looking for collinearity. A second linear regression was made for the final match outcome on home and away games. In both linear regressions the same variables were used (except field surface, since teams playing home always do it on their field). The used model is the following: $M 0=\beta 1+\beta 2 * S F+\beta 3 * Q 0+\beta 5 * S+\beta 5 * C+\beta 5 * G F S+\varepsilon i$

Statistical analyses were performed using SPSS 22.0 for windows (Inc, Chicago, IL, USA). Statistical significance was set at $p<.05$.

\section{Results}

The descriptive statistics and percentages of every game played during regular season, according to the match outcome and game location, can be seen on table 1 . The home teams, when they win, score the first goal on the $79.4 \%$ of the times, they make more substitutions (67.3\%) and receive less cards than the opposite team (66.7\%). When home teams don't score the first goal, winning chances drop to a $21.7 \%$. If the away teams score the first goal, they win $63.3 \%$ of their games, they do more substitutions when they loss or tie, and get less cards. If the home teams don't score the first goal, they just win $21.7 \%$ of their games.

Table 2 shows the results of linear regressions when the outcome of the match and final standings are predicted. These regressions explain the $45 \%$ of the variance for the final match outcome and final league standings. Equations, with the B-values explaining the contribution of
Table 1.

statistics and percentage of winners teams according to competition phase, scoring irst and match

\begin{tabular}{|cccccc}
\multicolumn{2}{c}{ Win } & \multicolumn{2}{c}{ Tied } & \multicolumn{2}{c}{ Lose } \\
\hline Home & Away & Home & Away & Home & Away \\
\hline$n(\%)$ & $n(\%)$ & $n(\%)$ & $n(\%)$ & $n(\%)$ & $n(\%)$
\end{tabular}

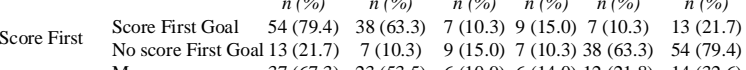

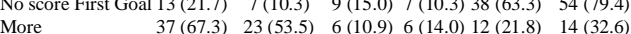

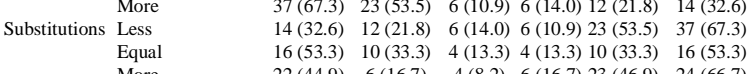

\begin{tabular}{llcccccc} 
& Equal & $16(53.3)$ & $10(33.3)$ & $4(13.3)$ & $4(13.3)$ & $10(33.3)$ & $16(53.3)$ \\
& More & $22(44.9)$ & $6(16.7)$ & $4(8.2)$ & $6(16.7)$ & $23(46.9)$ & $24(66.7)$ \\
\multirow{2}{*}{ Cards } & Less & $24(66.7)$ & $23(46.9)$ & $6(16.7)$ & $4(8.2)$ & $6(16.7)$ & $22(44.9)$
\end{tabular}

\begin{tabular}{llllllll}
\multirow{3}{*}{ Cards } & Less & $24(66.7)$ & $23(46.9)$ & $6(16.7)$ & $4(8.2)$ & $6(16.7)$ & $22(44.9)$ \\
& Equal & $21(48.8)$ & $16(37.2)$ & $6(14.0)$ & $6(14.0)$ & $16(37.2)$ & $21(48.8)$ \\
\hline
\end{tabular}

Table 2.

Effects of scoring first, match location, quality of opposition, playing in different surface, substitutions and cards on match outcome, week classification and final classification in youth league (no standardized beta coefficients, standard error and standardized ß into parentheses).

\begin{tabular}{lccccccc}
\hline & \multicolumn{3}{c}{ Macth outcome } & \multicolumn{3}{c}{ Final } \\
\hline & $B(S E)$ & $\beta$ & & $B(S E$ & $B$ & \\
\hline Constant & $-2.02(.58)$ & & & $8.45(.58)$ & & \\
Scoring First & $3.08(.35)$ & .43 & $* *$ & $-.90(.33)$ & -.13 & $* *$ \\
Match Location & $1.32(.39)$ & .18 & $* *$ & $.06(.38)$ & .01 & \\
Quality of Opposition & $-.18(.03)$ & -.28 & $* *$ & $.40(.03)$ & .56 & $* *$ \\
Substitutions & $.20(.10)$ & .10 & $*$ & $-.37(.09)$ & -.19 & $* *$ \\
Cards & $-.34(.10)$ & -.15 & $* *$ & $-.01(.10)$ & -.00 & \\
Surface & $.10(.48)$ & .03 & & $.14(.48)$ & .01 & \\
Durbin-Watson & 2.20 & & & 2.09 & & \\
$R^{2}$ & .45 & & & .45 & & \\
Numbers of observations & 256 & & & 256 & & \\
\hline
\end{tabular}
${ }^{*} p<.05 ; * * p<.01$

Table 3.

Effects of scoring first, quality of opposition, playing in different surface, substitutions and cards on match outcome when play at home or away (no standardized beta coefficients, cards on match outcome when play at home or away

\begin{tabular}{|c|c|c|c|c|c|c|}
\hline & \multicolumn{3}{|c|}{ Home } & \multicolumn{3}{|c|}{ Away } \\
\hline & $B(S E)$ & B & & $B(S E)$ & $\beta$ & \\
\hline Constant & $-.01(.68)$ & & & $2.98(.82)$ & & \\
\hline Scoring First & $2.41(.41)$ & .34 & ** & $3.33(.53)$ & .48 & ** \\
\hline Quality of Opposition & $-.38(.04)$ & -.52 & $* *$ & $-.13(.05)$ & -.19 & * \\
\hline Substitutions & $.12(.11)$ & .06 & & $-24(.16)$ & .11 & \\
\hline Cards & $-.34(.12)$ & -.16 & ** & $-.12(.18)$ & -.05 & \\
\hline Surface & & & & $-.02(.55)$ & -.00 & \\
\hline Durbin-Watson & 1.99 & & & 2.15 & & \\
\hline$R 2$ & .61 & & & .37 & & \\
\hline Numbers of observations & 128 & & & 128 & & \\
\hline
\end{tabular}

every variable (medium change in the dependent variable for each unit of change in predicting variables), are the following:

$M O=-2.02+(3.01 * S F)+(1.52 * M L)+(-.26 * Q 0)+$

$(.20 * S)+(.27 * C)+(-.40 * G F S)+\varepsilon i$

$F L S=8.48+(-.90 * S F)+(.06 * M L)+(.40 * Q 0)+(-.37 * S)+(-$ $.01 * C)+(.14 * G F S)+\varepsilon i$

In the final outcome of every game, scoring first, game location and number of substitutions are found to be significant variables with positive values, and the rival's quality and the amounts of cards with negative values (Table 2). If the team scores first, plays home, and does more substitutions, the final goal score difference is increased. In addition, if the quality of the rival team is lower, and gets less cards than the opposition, the goal difference keeps growing. On the other hand, when studying the final league standings, it is shown that scoring first and a higher number of substitutions will improve the team's final standings. Likewise, the rival's quality has a prediction effect on the final standings, the less quality of the rival team, the better the standings. Addressing the standardized â coefficients (relative importance of each variable information), scoring first is the most important variable for the outcome of the game, meanwhile the quality of the opposition is the most relevant variable on the final league standings.

In the competition study according to the game location, the influence of situational variables is similar to the ones found through the entire competition. Scoring first is important for the game's final outcome, but its importance is higher when playing away. The rival team's quality also predicts the final outcome. In this case, when playing away, is better when the difference between the teams is less. Finally, the amount of cards has a negative influence on the match outcome on home teams, meanwhile it doesn't influence the final score on away teams (Table 3). On the other hand, standardized â coefficients show that the rival team's quality is the most important variable while playing home, whereas, while playing away, the most important variable is scoring first. 


\section{Discussion}

The goal of this study was to analyze the effect of situational variables on the performance in U'18 soccer. The absence of scientific literature that analyzes the sport performance indicators in training periods causes the need of a double effort in the results discussion. In one hand, analyzing the results in the studied competition context, and on the other hand, contrasting them with high-level competition.

The results reveal the importance of the game's location, scoring first, opponent's quality, substitutions and cards have on the final outcome of the match, while in the final league standings, the linear regression highlights the importance of scoring the first goal, rival team's quality and substitutions.

Scoring the first goal is the strongest predictor on the result in any produced model. Sports where the final score is low, like soccer or ice hockey, show the importance of scoring the first goal (García-Rubio et al., 2015; Jones, 2009; Lago, 2005). In the four most important soccer leagues in Europe, the number of goals per game is just 2.66 (Anderson \& Sally, 2013), increasing the relevance of scoring first. The analyzed competition, the number of goals per game is 7.24 , a considerable amount. Even so, the importance of the first goal is as relevant as it is on professional competition. Scoring first has a direct impact on teams' behavior, since teams play differently according to the score. Teams who are ahead in the score, play a more conservative soccer game, preventing the scoring opportunities of the rival team (Lago, 2009), which reduce the amount of shots (Taylor, Mellalieu, James, \& Shearer, 2008). In fact, teams that score first show the same performance indicators profile (shots on target, shots off target, corner kicks ...) as the winning teams (García-Rubio etal., 2015; Lago-Peñas \& Lago-Ballesteros, 2011). On the other hand, even though the low attendance to this kind of competitions could made it appear as if the game's location isn't as important as in other competitions, it has been found that, in this competition, it is a strong predictor on the final match outcome (Taylor et al., 2008). Scoring first makes that the local fans get encouraged and their support has a positive impact on the home team, meanwhile the effect is negative on the away team's players (Courneya, 1990). Besides, playing home makes the home team's players experience a territorial reaction, of defense of their territory (Pollard \& Gómez, 2009).

The opponent's quality is another one of the performance predictor situational variables, both in the outcome of the game, when they play home or away, as in the final league standings. In the high-performance soccer, the opposed team's quality has a significant value but with low impact (García-Rubio et al., 2015), while in this competition it has a more important value. It has been stablished that the joint effect of other situational variables, such as the game's location and the effect of scoring first, can soften the effect of the opponent team's quality in high level leagues (Lago-Peñas \& Lago-Ballesteros, 2011). The results on these study show, that on underage leagues, the rival team's quality has an important effect on the performance, regardless of the interactive effect of the other situational variables.

Finally, results reveal the importance of the number of substitutions on the outcome of the match and in the final league standings. Players that enter the game field during the match, regardless of whether it is an early or a late substitution, increase the distance covered at high intensity in a 15\% (Bradley \& Noakes, 2013), especially if they are midfielders (Carling, Espié, Le Gall, Bloomfield, \& Jullien, 2010). It has been proved that covered distance prior a goal in high intensity efforts is increased in the scoring team, highlighting the importance of substitution to maintain a high fitness level on the players (Hinojosa \& Castellano, 2017)

Moreover, the amount of cards is a negative predictor on the outcome of the game, and in the home played games. Teams that are sanctioned with a sendoff due to cards, suffer a decrease in the amount of goals and in the final match outcome as of the punishment (Bar-Eli et al., 2006). Teams will suffer a performance decline when a player is send off. In addition, players that are booked, experiment a decrease in their performance due to the chance of another yellow card that would led to a sendoff, not only from that game, but from the next one that carries the sendoff sanction. This makes cards predictors of the game's outcome.

The game-field surface has not been expressed as a situational variable that condition the outcome of the match. There are no studies with qualified samples that show incidence of this variable on the overall performance. There are difference in some of the performance indicators in different studies. In harder surfaces more passes happen, meanwhile in softer surfaces more aerial situations occur (Sleat et al., 2016). Furthermore, differences between the number of passes and sliding tackles have been found between natural and artificial grass (Andersson, Ekblom, \& Krustrup, 2008). The results show that the game-field surface influence the team's playstyle, but, it has been found also, that the possession based playstyle has more relation with success (Kempe, Vogelbein, Memmert, \& Nopp, 2014), most goals are scored after a sequence of at least three passes (Reep \& Benjamin, 1968).

Finally, results highlight the importance of situational variables on the performance in youth soccer. Scoring first, the opponent's quality and the amount of cards are variables that affect and stress players, especially during adolescence (Reeves, Nicholls, \& McKenna, 2009). Results show that the impact of these variables is more important than in professional leagues. This might be because when clubs do the players selection for the youth categories they focus more on technical, tactical and physiological aspects rather than the psychological aspects (Huijgen, Elferink-Gemser, Lemmink, \& Visscher, 2014). Then, when they face an adverse situation, is harder to get a favorable result.

\section{Conclusions}

This paper shows the interactive effects of the situational variables on youth soccer, scoring first, game's location, the opponent's quality, substitutions and cards. Home teams, that score first, with a better weekly standings, and that makemore substitutions, have more chances of winning the game. These results help trainers to prepare different strategies according to the competition's stage, adapting the team's needs to the specific context. In order to do that, trainers could design training scenarios where they start with a goal against or in favor, with more or less booked players, situations that in the quality of the teams, for that task, are uneven, or the conjunction of multiple scenarios at the time. Finally it is very important to keep developing an investigation line that analyses the performance indicators on different populations, contexts and genders than the high performance male competitions, so their results have a larger applicability and transference.

\section{Acknowledgments}

This work have been partially supported by the "Ayuda a los Grupos de Investigación (GR15122)” of Govern of Extremadura (Economy and Infrastructures Department); With the support of European Union through FEDER founds

\section{References}

Aguiar, M., Goncalves, B., Botelho, G, Lemmink, K., \& Sampaio, J. (2015). Footballers' movement behaviour during 2-, 3-, 4- and 5-a-side small-sided games. Journal of Sports Sciences, 33(12), 1259-1266. doi: 10.1080/02640414.2015.1022571

Anderson, C., \& Sally, D. (2013). The numbers game: why everything you know about football is wrong: Penguin UK.

Andersson, H., Ekblom, B., \& Krustrup, P. (2008). Elite football on artificial turf versus natural grass: movement patterns, technical standards, and player impressions. Journal of Sports Sciences, 26(2), 113-122.

Ato, M., López, J. J., \& Benavente, A. (2013). Un sistema de clasificación de los diseños de investigación en psicología. Anales de Psicología, 29(3), 1038-1059.

Bar-Eli, M., Tenenbaum, G., \& Geister, S. (2006). Consequences of players' dismissal in professional soccer: Acrisis-related analysis of group-size 
effects. Journal of Sports Sciences, 24(10), 1083-1094.

Bradley, P. S., \& Noakes, T. D. (2013). Match running performance fluctuations in elite soccer: Indicative of fatigue, pacing or situational influences? Journal of Sports Sciences, 31(15), 1627-1638.

Brocherie, F., Girard, O., Faiss, R., \& Millet, G. P. (2015). High-intensity intermittent training in hypoxia: a double-blinded, placebo-controlled field study in youth football players. The Journal of Strength \& Conditioning Research, 29(1), 226-237.

Carling, C., Espié, V., Le Gall, F., Bloomfield, J., \& Jullien, H. (2010). Work-rate of substitutes in elite soccer: A preliminary study. Journal of Science and Medicine in Sport, 13(2), 253-255.

Coelho, D. B., Coelho, L. G. M., Morandi, R. F., Ferreira Junior, J. B., Marins, J. C. B., Prado, L. S., . . Silami-Garcia, E. (2012). Effect of player substitutions on the intensity of second-half soccer match play. Revista Brasileira de Cineantropometria \& Desempenho Humano, 14(2), 183-191.

Courneya, K. S. (1990). Importance of game location and scoring first in college baseball. Perceptual and Motor Skills, 71(2), 624-626.

Drust, B. (2010). Performance analysis research: Meeting the challenge. Journal of Sports Science.

Folgado, H., Lemmink, K. A., Frencken, W., \& Sampaio, J. (2014). Length, width and centroid distance as measures of teams tactical performance in youth football. European Journal of Sport Science, 14(sup1), S487-S492.

García-Rubio, J., Gómez, M. Á., Lago-Peñas, C., \& Ibáñez, S. J. (2015) Effect of match venue, scoring first and quality of opposition on match outcome in the UEFA Champions League. International Journal of Performance Analysis in Sport, 15, 527-539.

García, J., Ibáñez, S. J., Feu, S., Cañadas, M., \& Parejo, I. (2008). Estudio de las diferencias en el juego entre equipos ganadores y perdedores en etapas de formación en balonmano.(Study of the differences yn play between winning and losing teams in formative stages of team handball). CCD. Cultura_Ciencia_Deporte. $\ddagger e S-N \tilde{N} y \bullet b-S O^{2} \bullet$ doi: 10.12800/ccd, 3(9), 195-200.

García, J., Ibáñez, S. J., Gómez, M. A., \& Sampaio, J. (2014). Basketball Game-related statistics discriminating ACB league teams according to game location, game outcome and final score differences. International Journal of Performance Analysis in Sport, 14(2), 443-452.

Gómez, M.-A., Lorenzo, A., Ibáñez, S.-J., \& Sampaio, J. (2013). Ball possession effectivenessinmen's and women's elite basketball according to situational variables in different game periods. Journal of Sports Sciences, 31(14), 1578-1587.

Gómez, M., Lago-Peñas, C., \& Pollard, R. (2013). Situational variables. Routledge Handbook of Sports Performance Analysis, 259-269.

Gómez, M. A., Gómez-Lopez, M., Lago, C., \& Sampaio, J. (2012). Effects of game location and final outcome on game-related statistics in each zone of the pitch in professional football. European Journal of Sport Science, 12(5), 393-398.

Gómez, M. Á., Serna, A. D., Lupo, C., \& Sampaio, J. E. (2016). Effects of Game Location, Quality of Opposition, and Starting Quarter Score in the Outcome of Elite Water Polo Quarters. The Journal of Strength \& Conditioning Research, 30(4), 1014-1020.

Hinojosa, A \& Castellano, J. (2017) Influencia de la distancia recorrida en diferentes rangos de velocidad en la anotación de un gol en fútbol (Influence of the distance covered at different speed ranges on scoring goals in soccer). Retos, (31), 188-192.

Huijgen, B. C., Elferink-Gemser, M. T., Lemmink, K. A., \& Visscher, C. (2014). Multidimensional performance characteristics in selected and deselected talented soccer players. European Journal of Sport Science, 14(1), 2-10.

Jones, M. B. (2009). Scoring first and home advantage in the NHL. International Journal of Performance Analysis in Sport, 9(3), 320331.

Kempe, M., Vogelbein, M., Memmert, D., \& Nopp, S. (2014). Possession vs. direct play: Evaluating tactical behavior in Elite Soccer. International Journal of Sports Science, 4(6A), 35-41.

Kristenson, K., Bjørneboe, J., Waldén, M., Ekstrand, J., Andersen, T. E., \& Hägglund, M. (2015). No association between surface shifts and time-loss overuse injury risk in male professional football. Journal of Science and Medicine in Sport.
Lago-Peñas, C., \& Lago-Ballesteros, J. (2011). Game location and team quality effects on performance profiles in professional soccer. Journal of Sports Science and Medicine, 10(3), 465-471.

Lago, C. (2005). To win or to lose in soccer: A matter of performance or chance. European Journal of Human Movement, 14, 137-152.

Lago, C. (2009). The influence of match location, quality of opposition, and match status on possession strategies in professional association football. Journal of Sports Sciences, 27(13), 1463-1469.

Liu, H., Gómez, M.-A., Gonçalves, B., \& Sampaio, J. (2015). Technical performance and match-to-match variation in elite football teams. Journal of Sports Sciences, 1-10.

Liu, H., Hopkins, W. G, \& Gómez, M.-A. (2015). Modelling relationships between match events and match outcome in elite football. European Journal of Sport Science, 1-10.

Lorenzo, A., Gómez, M. Á., Ortega, E., Ibáñez, S. J., \& Sampaio, J. (2010). Game related statistics which discriminate between winning and losing under-16 male basketball games. Journal of Sports Science and Medicine, 9(4), 664-668.

Marcelino, R., Mesquita, I., \& Sampaio, J. (2011). Effects of quality of opposition and match status on technical and tactical performances in elite volleyball. Journal of Sports Sciences, 29(7), 733-741.

Pic, M., \& Castellano, J. (2017). Influence of match location in the spanish Copa del Rey. Retos, 31, 202-206.

Pollard, R., \& Gómez, M. A. (2009). Home advantage in football in South-West Europe: Long-term trends, regional variation, and team differences. European Journal of Sport Science, 9(6), 341-352. doi: 10.1080/17461390903009133

Prieto, J., Gómez, M.Á., \& Sampaio, J.(2016). Game-scoring coordination in handball according to situational variables using time series analysis methods. International Journal of Performance Analysis in Sport, 16(1), 40-52.

Randers, M., Andersen, T. B., Rasmussen, L., Larsen, M. N., \& Krustrup, P. (2014). Effect of game format on heart rate, activity profile, and player involvement in elite and recreational youth players. Scandinavian Journal of Medicine \& Science in Sports, 24(S1), 1726.

Rebelo, A., Brito, J., Seabra,A., Oliveira, J., \& Krustrup, P. (2014). Physical match performance of youth football players in relation to physical capacity. European Journal of Sport Science, 14(sup1), S148-S156.

Reep, C., \& Benjamin, B. (1968). Skill and chance in association football. Journal of the Royal Statistical Society. Series A (General), 131(4), 581-585.

Reeves, C. W., Nicholls, A. R., \& McKenna, J. (2009). Stressors and coping strategies among early and middle adolescent premier league academy soccer players: Differences according to age. Journal of Applied Sport Psychology, 21(1), 31-48.

Rey, E., Lago-Ballesteros, J., \& Padrón-Cabo, A. (2015). Timing and tactical analysis of player substitutions in the UEFA Champions League. International Journal of Performance Analysis in Sport, 15(3), 840-850.

Sampedro, J., \& Prieto, J. (2012). El efecto de marcar primero y la ventaja de jugar en casa en la liga de fútbol y en la liga de fútbol sala de España. Revista de Psicología del Deporte, 21(2), 301-308.

Siegle, M., \& Lames, M. (2012). Game interruptions in elite soccer. Journal of Sports Sciences, 30(7), 619-624.

Sleat, W., O’Donoghue, P., Hughes, M., \& Bezodis, I. N. (2016). The influence of natural grass surface hardness on path changes, locomotive movements and game events in soccer: a case study. International Journal of Performance Analysis in Sport, 16(1), 216-233.

Taylor, J. B., Mellalieu, S. D., James, N., \& Shearer, D. A. (2008). The influence of match location, quality of opposition, and match status on technical performance in professional association football. Journal of Sports Sciences, 26(9), 885-895.

van den Eijnde, W. A., Peppelman, M., Lamers, E. A., van de Kerkhof, P. C., \& van Erp, P. E. (2014). Understanding the Acute Skin Injury Mechanism Caused by Player-Surface Contact During Soccer A Survey and Systematic Review. Orthopaedic Journal of Sports Medicine, 2(5), 2325967114533482. 